\title{
SOBRE GREVE, LIBERDADE E RINOCERONTES
}

\author{
Eros Sester ${ }^{1}$ \\ Sara Vieira Antunes²
}

RESUMO: Partindo do contexto da greve de 2016 na Unicamp, marcado por um ambiente politicamente frágil e acirramento entre diferentes atores/atrizes no embate institucional e civil, o presente texto propõe uma análise crítica da montagem "Canto para Rinocerontes e Homens", encenada no referido ano pela companhia Teatro do Osso. Baseada na dramaturgia "O Rinoceronte" de Eugène Ionesco, a peça que aqui serve de emblema revela e retorce uma série de contradições explícitas e implícitas na onda de conservadorismo que tem acompanhado a crise econômica e a irresponsável e indecente gestão política institucional. Elaborada por mestres em formação durante o período da greve, a resenha é elaborada como um diálogo-debate e redigida colaborativamente em um estilo ensaístico, e reflete em sua forma a elaboração de um espaço onde as normas acadêmicas de produção do conhecimento científico puderam ser colocadas em perspectiva. Esperamos, com o texto que segue, provocar reflexões nos/as leitores/as atinentes aos próprios valores e convicções que tem governado nossas concepções acerca do humano e dos mundos que queremos.

PALAVRAS-CHAVE: greve, teatro, liberdade, humano, universidade, rinocerontes, crítica cultural.

"Cotas sim, cortes não. Contra o golpe e pela educação. Por moradia, ampliação e transparência”. Esse é o mote que levou grande parte dos/ as alunos/as, funcionários/as e professores/as da Universidade Estadual de Campinas a entrarem em greve no ano de 2016. As insatisfações são

1 Mestrando em Antropologia Social pelo PPGAS-IFCH da UNICAMP. E-mail: eros.sester@ gmail.com

2 Mestranda em Antropologia Social pelo PPGAS-IFCH da UNICAMP. E-mail: saraantunes13@gmail.com 
inúmeras e não são de agora. Mas, diante do cenário político e econômico do país dos últimos três anos, essas insatisfações ganharam novas e graves proporções. $\mathrm{O}$ aparente projeto político de desmonte da educação pública de qualidade levou secundaristas a ocuparem escolas por todo o estado de São Paulo, ecoando e trazendo à superfície problemas estruturais em todo o país no que diz respeito ao repasse de verba às escolas, salários dos professores/as, merendas, condições materiais e recursos básicos para a sala de aula.

A universidade pública, como espaço de produção de conhecimento acadêmico, tem sido vitimada pela crise política e econômica, sobretudo nas áreas em que o retorno financeiro é modesto e não imediato. Para além disso, a dificuldade de acesso de segmentos desfavorecidos nestas universidades alerta a necessidade de problematizar esse sistema de seleção e buscar condições não apenas para a sua inserção, mas para a sua manutenção durante o período de estudo. O descompasso entre a qualidade de formação oferecida pelo ensino público fundamental e o grau de exigência para a entrada nas universidades públicas demonstra serem estes espaços privilegiados para aqueles/as que possuem condições de pagar por um ensino privado e cursinhos preparatórios. O próprio formato que possibilita a entrada de pessoas na universidade coloca restrições estruturais que promovem uma clara seleção de classe, bem como não disponibiliza condições materiais necessárias para a manutenção dessas pessoas na universidade.

Dessa forma, o debate sobre cotas na universidade e pela permanência desses/as alunos/as tornou-se um dos motes centrais da greve do ano passado. Discussões sobre cotas sociais e raciais, pela ampliação e reforma da moradia estudantil e pela transparência nos gastos da universidade estavam alinhadas como temas centrais que balizaram a greve estudantil, todos intimamente ligados. Ao reivindicar transparência no que diz respeito aos gastos da universidade abre-se precedentes para discutir medidas concretas para possibilitar não apenas o acesso, mas a manutenção de alunos/as que historicamente estiveram apartados desses espaços. 
Foi dentro deste cenário de discussões que os/as aluno/as de pósgraduação do Instituto de Filosofia e Ciências Humanas (IFCH) aderiram à greve, somando-se aos/às funcionários/as e também professores/ as. A disciplina de Gênero e Sexualidade ministrada pelas professoras Isadora Lins França e Carolina Branco, depois de um encontro onde foram discutidos os encaminhamentos no contexto da greve, converteuse em um espaço de encontro para discutir questões mais amplas sobre o contexto político do país e sobre as demandas da greve. Optamos por fazer encontros abertos quinzenais, dentro da programação da greve, focando em questões concernentes aos temas de gênero e sexualidade dentro dessa conjuntura.

Esse expediente permitiu com que o grupo se fortalecesse em termos de intimidade e proximidade, favorecendo um ambiente acolhedor para a construção coletiva de um novo projeto a partir da disciplina, amparado por trocas, relatos e reflexões contínuas. Sem saber exatamente o rumo que tomaríamos, iniciamos com tempestades de ideias e incômodos que inquietavam a todos/as, semanalmente estarrecidos pelos acontecimentos políticos, sobretudo no período de forte campanha pró-impeacbment e com a entrada do governo Temer. Nesse turbilhão de ideias, decidimos por produzir textos e vídeos que pudessem ser facilmente veiculados nas mídias sociais, de forma a difundir e "viralizar" as reflexões produzidas coletivamente.

Entre esses encontros fui assistir a uma peça de teatro em São Paulo com alguns/umas amigos/as desse grupo. A peça, chamada "Canto para Rinocerontes e Homens", apesar de ser inspirada na peça "O Rinoceronte" de Eugène Ionesco, que tratava de questões relacionadas à alienação nas sociedades modernas (cujo mais temido epíteto seria o totalitarismo nazista), encontrava (não surpreendentemente) enorme ressonância com muitas das questões e problemáticas vividas no contexto político atual do país, que nos inquietavam ${ }^{3}$. Bastante envolvida e entusiasmada com a peça, senti o impulso de compartilhar e transmitir aos/às colegas do grupo

\footnotetext{
${ }^{3}$ Recomendamos fortemente a audiência presencial. Contudo, há uma filmagem do espetáculo disponibilizada desde o fim do ano retrasado na rede. Cf. https://vimeo.com/149689924.
} 
formado a partir da disciplina o que havia experienciado com a mesma. No encontro subsequente, debatíamos a necessidade de escrever mais livremente sobre as questões relativas à greve e ao cenário político que vivíamos, sem engessarmos tanto nossos dedos em amarras acadêmicas. Voluntariei-me a escrever algo a respeito da peça que havia assistido, ainda bastante receosa com a possibilidade de falar sobre algo fora da moldura segura e previsível das convenções acadêmicas.

A experiência de escrita foi libertadora. Sem preocupar-me com referências, demasiados cuidados históricos e com o receio de colocações pessoais e de engajamento político, respirei. Pela primeira vez em tempos me senti apropriada, engajada, entusiasmada em de fato colocar o que penso, sinto e pulso diante de cóleras há tempos reprimidas. Usei esses sentimentos de raiva, indignação, inconformidade e despejei-os no texto. Misturei minhas percepções sobre a peça com latências pessoais que se encontravam e embaralhavam-se, resultando em um texto bastante passional.

No encontro com o grupo, no dia seguinte, conversamos bastante e decidimos por compartilhar os textos que havíamos produzido. Li em voz alta a todos/as e senti mais uma vez o alívio e oxigenação de ter condições e incentivo para aquele tipo de escrita. Animados com as manifestações compartilhadas, decidimos, portanto, um próximo encontro onde iríamos filmar as falas de cada um a respeito do golpe contra o governo Dilma, fora algumas produções paralelas sobre questões adjacentes.

Ao invés de levar adiante aquele texto, uma leitura bastante pessoal e particular da peça, ainda que respaldada em muitas das questões políticas discutidas, decidi unir esforços junto a um grande amigo e colega de turma, Eros, para compartilharmos conjuntamente as impressões sobre os efeitos da greve e também da peça nas nossas escritas e reflexões. Como toda obra de arte, tivemos diferentes leituras da mesma peça, informada por nossas subjetividades, históricos pessoais, inquietações particulares. Contudo, vislumbrávamos um problema comum que a ambos alarmava: a notória semelhança de representações da peça em relação a fenômenos decorrentes de governos ditatoriais e o contexto político brasileiro atual. A leitura das condições sociais e políticas de embrutecimento e retrocessos 
em relação a direitos sociais fundamentais fazia-nos ver sementes brotando de mais uma possível sociedade formada por rinocerontes.

Ao refletir sobre o atual contexto político, o que víamos? Perda de inúmeros direitos arduamente conquistados por minorias sociais; precarização ainda mais pungente da educação pública do país; índices exorbitantes de encarceramento; fortalecimentos de bancadas evangélicas e reacionárias nas cadeiras dos altos cargos da cúpula do Estado. Para além disso, a evidente e escandalosa manipulação das grandes mídias para não apenas criar um inimigo público - "a corrupção" - e travesti-la de camisas vermelhas com uma grande estrela no meio, como, mais uma vez, forjar a ideia de uma "união patriótica" pelas cores verde e amarela em favor de um recorte social bem específico - branco, classe média/alta e heterossexual.

Essa mescla de indignação e temor diante do cenário que se nos apresenta emergiu diante dos nossos olhos por meio da performance singular de cada atriz e ator durante a peça "Canto para Rinocerontes e Homens". Motivados e comovidos por ela, trazemos aqui algumas reflexões, partindo das nossas diferentes - ainda que complementares - percepções acerca das possíveis representações do que poderia ser entendido como tornar-se rinoceronte. Passo a palavra, na próxima seção, para Eros.

\section{“RINOCERONTES DE NÓS MESMOS/AS”, EROS}

Senti que devia levar a maior quantidade de afins para compartilhar da inquietude que o espetáculo havia suscitado em mim. Insisti tanto, tanto, que até Sara, que mora em Campinas, acabou vindo para São Paulo só para assistir à peça. Pouco tempo depois ela me apresentou um texto que havia produzido sobre a mesma. Iniciou-se aí um debate sobre que leituras eram possíveis e rentáveis a partir da experiência. Como nossa querela se flagrasse frutífera, Sara me convidou para, no curso das atividades propostas no âmbito da greve, compor junto este texto em que ora fazemos uma resenha livre, traçando também uma linha entre as questões que nos mobilizaram e as evocadas no expediente da greve. 
Optamos, aqui, por costurar nossas leituras na forma de um debate onde nossas vozes, não se fundindo completamente, agregassem em uma aposta pelo diálogo.

Como resposta à significativa demanda do público, o espaço cênico Galpão do Folias articulou a extensão da temporada da peça "Canto para Rinocerontes e Homens" para mais um fim de semana, início de junho de 2016. Encenada por uma turma recém-egressa da Escola de Artes Dramáticas da Universidade de São Paulo, o Teatro do Osso, dirigido por Rogério Tarifa, notabilizou-se na cena paulistana por uma adaptação de um clássico da dramaturgia do século XX chamado "O Rinoceronte", de Eugène Ionesco. Alinhada à estética modelar do teatro do absurdo, a peça, que tematiza o processo de alienação de massas em sociedades modernas, faz, na leitura do Teatro do Osso, alegoria à convulsão social que resultou na hegemonização do pensamento nazista alemão durante o III Reich.

Bérenger é o sobrevivente de uma epidemia que terminou por transformar todas as pessoas em rinocerontes, e a peça narra como se dá esse processo. A leitura que culminou na montagem de "Canto para Rinocerontes e Homens" trabalha com a sugestão de que existe um substrato comum entre a alegoria original e a evocada pela montagem em si. Nesse sentido, o processo colaborativo foi ao mesmo tempo preciso e ferino ao desvelar uma série de chagas sociais deflagradas pelo recrudescimento de certas frentes ideológicas e coletivos organizados no rastro dos motins de 2013.

Assim, o argumento que reúne tanto a perplexidade frente ao sonho pangermanista quanto o nosso conhecido crescente descrédito em relação aos direitos humanos e à pluralidade de visões de mundo, é a construção de um inimigo público, chancelada por uma retórica moralmente informada por princípios que considero fascistas. Contudo, se a construção desse inimigo público outrora resultava em efeitos de bipolarização (cujo exemplo gritante é a tragédia nazista), ela se torna muito mais delicada e complexa na conjuntura atual.

Um jovem negro, proveniente de um bairro de periferia, comete um pequeno furto no centro da cidade, onde agride uma mulher. Capturado pela polícia militar, ele pode ter sido morto pela mesma. Um jovem rinoceronte, 
solto pela cidade, comete um furto, chifra uma mulher. Enjaulado, é assassinado por outros rinocerontes. Quem, afinal de contas, o matou? Ele mesmo? A polícia? A mulher? É essa a perplexidade que se nos acerca: a generalização do devir-rinoceronte. Para além da espetacularização das relações sociais e do esvaziamento das massas, banalizamos aquilo que é o caldo turvo do caos urbano: a brutalização.

De quem é o corpo que se desmonta e remonta? A quem pertence? À magazine ou a mim? O que é esse animal chamado sucesso? Essa dor de cabeça que dói, dói, dói pra caralho, é vertigem do trabalho ou um chifre que irrompe sem pedir permissão? (Senão a vertiginosa escala de trabalho dos/as professores/as de escolas públicas, e as grades disciplinares e suas jaulas). E esse sangue vertido, é o corpo esquartejado da travesti, ou o desejo refreado de ser quem não se pode ser? Estocada ou hemorragia?

Self-made man, apelo obcecado ao autoconhecimento, discursos intolerantes, esquizofrenia, miséria, prostituição, homo-lesbo-transbi-fobia, sucateamento do ensino, loucura, ocupações e reintegrações, escolas insurgentes e bombas de gás lacrimogêneo, racismo, luta pela sobrevivência, extinção, padrões de beleza, sexismo, crimes de ódio, tecnologias de assujeitamento, espetáculo, enxaqueca, perseguição, censura, polícia militar, classismo, operariado e desigualdade social... Sem nos darmos conta, envoltos pelo espetáculo e pelo caos urbano, acabamos nos tornando rinocerontes de nós mesmos/as.

Vista de cima, a cidade é, como na peça, uma arena onde é possível identificar a evolução da epidemia, isto é, o recrudescimento dos discursos intolerantes, e a batalha diária da massa esmagada de rinocerontes urbanos. Por ironia, a extinção dos rinocerontes brancos, cujos algozes são os homens, serve de contrapelo à narrativa. Como um remanescente espécime nativo, Bérenger, por razões a interpretar, olha ao redor e enxerga com perplexidade e resignação o que restou de um mundo onde, antes de rinocerontes, os humanos eram mais humanos.

O custo pelo não-contágio, enfim, é a solidão: a lucidez em um mundo onde ela definitivamente não é um valor.

Um mundo que pleiteia, aliás, a volta das formas totalitárias de poder, que clama pela produção de antagonismos e reivindica o assujeitamento 
e a purificação social, criando pânicos morais e forjando párias a partir de crises letais que ele mesmo criou, só pode estar padecendo de uma patologia crônica. A missão aí então é parar tudo isso, antes que seja tarde, e só restem ruínas e bestas à deriva.

Sara e eu pudemos atestar, ao assistir a peça, aquilo que consideramos ser um valor central dentro da produção artística que admiramos e defendemos: a capacidade de mobilizar para além do trivial. A arte-paraalém-da-savana-social. Damos prosseguimento ao debate, agora com as contribuições trazidas por ela, a partir de sua leitura da peça.

\section{“A BRUTALIZAÇÃO DO 'OUTRO': FABRICANDO RINOCERONTES", SARA}

A minha leitura da peça esteve invariavelmente informada pelo trabalho de campo que tenho realizado há cerca de um dois anos e meio em penitenciárias femininas. $\mathrm{O}$ contato com o contexto prisional trouxe à tona realidades antes consideradas mera ficção, pois desconsiderava haver ainda hoje, tão próximo (e ao mesmo tempo tão distante) condições tão absolutamente desumanas e brutais. A proteção vivida pelo meu contexto de criação e formação como mulher branca de classe média me apartava de realidades que via com estranhamento em uma distância segura através das cores e formas desenhadas na televisão.

Mas já sentia um incômodo. Incômodo esse que não sabia definir, nem encontrar sua origem, mas permeava meus interesses e buscas pessoais. Com a entrada na universidade o incômodo cresceu, passou a ganhar sentidos e crítica. Começou com o reconhecimento do lugar privilegiado de fala e percepção do qual partia. Ainda assim, entendia que isso não poderia me paralisar. Então, seria no papel e na militância que poderia encontrar vazão e sentido a essas sensações que me atravessavam e me impeliam a fazer algo a respeito.

$\mathrm{Na}$ peça, apesar de entender o contexto mais amplo de um corpo social embrutecido que transformava todos em rinocerontes, via também a fabricação acusativa que identificava somente no "outro" a transformação, outorgando a si mesmo o lugar de pessoa, de cidadã/o, civilizada/o. 
O bruto, o animalizado, o abjeto estaria sempre distante, como fonte de medo e recusa de uma imagem possivelmente espelhada.

Esse bruto, esse rinoceronte, quando toma as ruas, incomoda, assusta, causa confusão e violência. Uma calamidade! É perigoso, deve ser detido, as autoridades devem se atentar! Para isso, "cidadãos de bem" se revoltam, tomam as ruas, reivindicam "o seu direito" de não serem incomodados por esses seres vis. Batem panela, vestem verde e amarelo, saem de suas casas confortáveis para tomar as ruas - antes nunca ocupadas - para livrá-las de vez desses animais imundos que estão querendo acabar com a paz "de todos".

Detentores da força moral lutam raivosos contra todos aqueles que defendem a subsistência ultrajante desses rinocerontes. Estes devem permanecer enjaulados. Nas suas jaulas, nas suas celas, nas suas gaiolas, podem ser vistos de longe, sem incomodar. Podem até transitar de uma cadeia a outra de bonde, em camburões fechados onde mal se pode respirar, quanto menos serem vistos. Podem ficar nos barracos das favelas lá longe, nas periferias da cidade aonde nem o metrô chega, onde o ônibus leva horas para chegar. Lá, lá longe, eles não incomodam. Não incomodam sentados e quietos nas salas de aula desestruturadas e abandonas do estado, fechadas por grades e muros altos. Grades, celas, jaulas, gaiolas. Comportados e disciplinados, vão "no máximo" agredir alguns professores, abandonar a escola no ensino médio para trabalhar, para traficar, para roubar. Mas lá longe, naquelas quebradas que ninguém sabe o nome.

O problema é quando saem das jaulas. Longe dos zoológicos são amedrontadores. Tomam as ruas, invadem, dormem nas calçadas, roubam, furtam, assaltam, vivem importunando "cidadãos de bem" que só querem sair dos seus trabalhos e ir para casa. Matam "pais de família", "inocentes" por dinheiro, por ganância. O que querem eles? Roupas de marca, ostentação? São realmente muito fúteis. Para que tudo isso? Com dois carros na garagem, trocados a cada dois anos, roupas compradas no shopping, escolas particulares, médicos particulares e formação superior, morrem de medo desses seres fúteis e tão apegados ao dinheiro.

São bandidos. Ladrões. Escória da sociedade. Tem que sofrer na prisão! Devem pagar pelos seus atos, devolver "para a sociedade" o que 
dela tiraram. Na realidade, "bandido bom é bandido morto". A prisão, nesse sentido, cumpre bem o seu papel. Máquina de tortura e assassina dá continuidade ao trabalho bem sucedido da polícia militar contra seu maior alvo e inimigo: aqueles mesmos pretos e pobres que eram escravizados e brutalizados alguns séculos atrás. Esses rinocerontes... Ah, esses rinocerontes! Têm de entender o seu lugar!

O medo se confunde com o ódio e com a vontade de destruir aqueles que ameaçam a ordem moral estabelecida: "Homens de bem" que querem preservar a "tradicional família brasileira", "núcleo fundacional da ordem e da disciplina de um país". Questionar essa ordem torna-se uma ameaça concreta e assertiva na destruição dessa base fundacional e na previsão em curto prazo de absoluto caos social. "Ideologia de gênero", direitos e proteção à população LGBT, legalização do aborto, delegacias da mulher, meros caprichos de uma minoria que quer destruir a família tradicional brasileira! Aberrantes, promíscuos, lascivos, imorais, não são recomendados à sociedade. Rinocerontes, não são dignos de compaixão. Precisam ser eliminados do coração da sociedade.

Essas "vidas precárias", como coloca Judith Butler (2006), não são dignas de luto. São vidas esquecíveis, vidas que não merecem ou não precisam ser lembradas. Aparecem (quando aparecem) como números (em contínuo crescimento), nos dados da Organização Mundial da Saúde e em pequenos excertos de jornais. Não ganham as matérias de destaque, não aparecem no Jornal Nacional, pois isso tomaria tempo, tempo demais, haveria demasiadas mortes para se falar. Como diria Agamben, essas "vidas nuas" (2004) são vidas de corpos matáveis, e justamente por serem matáveis, não importam, não pesam, não precisam ser enlutadas. Nas palavras de Butler,

\footnotetext{
"essas populações são "perdíveis", ou podem ser sacrificadas, precisamente porque foram enquadradas como já tendo sido perdidas ou sacrificadas. São consideradas como ameaças à vida humana como a conhecemos, e não como populações vivas que necessitam de proteção contra a violência ilegítima do Estado, a fome e as pandemias. (...)
} 
A perda dessas populações é considerada necessária para proteger a vida dos "vivos" (BUTLER, 2015:53)"

Para os "vivos" é necessária proteção e cuidado de suas valiosas e preciosas vidas. $\mathrm{Na}$ desordem e baderna do cenário político atual, não existe mais "a mão de ferro" necessária para guiar e trazer disciplina, ordem e segurança a essas vidas. Estão todos corrompidos. A saída seria o (ainda maior!!) enrijecimento das forças militares para trazer lei e ordem a força, goela abaixo. Que volte a ditadura militar, que seja feita a "revolução militar", por Deus, pela família, pelo meu cachorro, minha avó, minha vizinha, meus amigos do futebol, pelo meu periquito José...

Como fora muito bem citado durante a peça, Hannah Arendt já dizia que "o espaço público é o espaço que preserva a ação do esquecimento". A peça "Canto para Rinocerontes e Homens" chama a atenção para algo realmente alarmante: estamos gradualmente ignorando a história, aquilo que veio antes de nós e o que nos tornou o que somos hoje. $\mathrm{O}$ espaço público, as vozes de representantes públicos da população (elegida democraticamente por ela), estão (só podem estar!) perdendo a memória. Cegos (como rinocerontes), surdos e esquecidos, as pessoas têm perdido o espaço público como lócus primordial para o diálogo, para ver, ouvir, ser visto e ouvido por outros. Por não ocupar os mesmos espaços, não se veem, não se escutam, não praticam a simples alteridade e empatia inerente ao (re)conhecimento mútuo de iguais.

O "outro", esse fantasma distante e assustador que não conheço, que só conheço de longe, que tenho um ou outro "exemplar" na família, um parente distante, um colega de turma, aqueles dois amigos do trabalho ou do futebol. Aqueles poucos do meu convívio que, quando sou acusado de preconceito, posso logo revidar e dizer com orgulho: "tenho um amigo assim".

Durante a peça, fizeram exibições de trechos de vídeos com falas de alguns pensadores. Em uma delas, José Saramago se questiona se nos tornamos todos nós, por fim, cegos. "Cegos da razão, cegos da sensibilidade, de tudo aquilo que nos faz ser razoavelmente funcionais no sentido da doação humana. Mostramo-nos, em realidade, seres 
egoístas, seres violentos. E o espetáculo que o mundo nos oferece mostra exatamente isso: um mundo de desigualdades, de sofrimento, sem justificação". O escritor sugere que apenas hoje, na era audiovisual, estamos realmente vivendo na caverna de Platão. Olhamos para fora (por meio de uma tela de computador, televisão ou celular) e vemos a sombra do mundo, e acreditamos que isso é a realidade. Essas imagens, de alguma maneira, substituem a realidade. Tornam-se a própria realidade. "Estamos infelizmente a repetir a situação das pessoas que estão atadas, aprisionadas na caverna de Platão, olhando em frente, vendo sombras e acreditando que essas sombras são a realidade”.

\section{“TUDO O QUE O DIABO ESQUECEU NO INFERNO É O COMUNISMO", SARA E EROS}

Em uma reportagem audiovisual veiculada no fim do ano retrasado durante uma manifestação pró-impeachment, algumas pessoas apareciam sendo entrevistadas. Em uma das falas, que consideramos emblemática, o "comunismo", bem como a pluralidade de pensamentos ditos de esquerda que aparecem reduzidas a esse guarda-chuva enigmático, era definido como "tudo o que o diabo esqueceu no inferno": uma leitura sintomática de um tempo em que antagonismos se condensam, e o fazer político em todos os seus meandros e poréns se vê atordoado pelo acirramento de disputas entre agendas. O espetáculo "Canto para Rinocerontes e Homens" toca porque escancara um conjunto desses pontos de estrangulamento da política e das convenções de humanidade/ bestialidade, evocando o perigo do espetáculo, a construção epidêmica e expiatória de um "outro" e a perplexidade de uma realidade onde, tão supostamente humanos, subitamente nos descobrimos rinocerontes.

Apesar de termos delineado nossas leituras em diferentes seções, este texto foi escrito de forma colaborativa, e não se presta à construção de uma crítica da peça propriamente dita, mas parte das nossas experiências

\footnotetext{
4 “Cunha é só boi de piranha. Quem manda é o Lula", tv Carta (da Carta Capital), publicado no YouTube em 20 de outubro de 2015. Cf. https:/ / www.youtube.com/watch?v=VLrqZC3H3DQ.
} 
como espectador e espectadora para a elaboração de um conjunto de reflexões que buscamos partilhar.

O contexto da greve, como espaço de discussão, reflexão e produção compartilhada de ferramentas de luta em papel, caneta e câmera, mostrou-se fundamental (em condições ímpares) para a produção deste texto. A oportunidade de criar e promover uma escrita crítica, ao mesmo tempo pessoal e passional, normalmente está restrita a blogs e conversas informais, espaços de troca livre de pensamentos. O grupo de trabalho formado a partir da disciplina de gênero e sexualidade forjou um lugar de acolhimento, dando condições para exercermos nossa liberdade para falar, trocar, produzir e escrever. Inclusive, sobre rinocerontes.

\section{REFERÊNCIAS BIBLIOGRÁFICAS}

AGAMBEN, G. Homo Sacer: o poder soberano e a vida nua I. Belo Horizonte: Ed. UFMG, 2004.

BUTLER, Judith. Vida precaria: el poder del duelo y la violência. Buenos Aires: Paidós, 2006.

- Quadros de guerra: quando a vida é passível de luto. Rio de Janeiro: Civilização Brasileira, 2015. 
